\title{
Effects of Anesthetic Agent Propofol on Postoperative Sex Hormone Levels
}

\author{
Wirkung des Anästhesiemittels Propofol auf den weiblichen \\ Sexualhormonspiegel nach einem chirurgischen Eingriff
}

Authors

Affiliation
H. Kim, S.-Y. Ku, H. C. Kim, C. S. Suh, S. H. Kim, Y. M. Choi

Department of Obstetrics and Gynecology, Seoul National University College of Medicine, Seoul, Republic of Korea

\section{Key words \\ - anesthesia \\ - sex hormone \\ - propofol \\ Schlüsselwörter \\ - Anästhesie \\ - Sexualhormon \\ - Propofol}

\section{received 29.7.2015 \\ revised 14.12.2015 \\ accepted 17.12.2015}

Bibliography

DOI http://dx.doi.org/

10.1055/s-0041-111571

Geburtsh Frauenheilk 2016; 76 :

408-412 @ Georg Thieme

Verlag KG Stuttgart · New York . ISSN 0016-5751

\section{Correspondence}

Seung-Yup Ku, MD, PhD

Department of Obstetrics

$\&$ Gynecology

Seoul National University

College of Medicine

28 Yonkeun-dong Chongno-gu

Seoul 110-744

Republic of Korea

jyhsyk@snu.ac.kr

\section{Abstract \\ $\nabla$}

Introduction: Several studies have found anesthetic agents including propofol in ovarian follicular fluid. However, little is known about the effect of anesthetic agents on ovarian function. We aimed to investigate whether there were differences in the postoperative levels of sex hormones when propofol was used as the anesthetic agent. Methods: A retrospective review was done of 80 patients who underwent ovarian surgery, with 72 infertile women serving as controls. Patients were included in the study if their serum estradiol (E2) and follicle stimulating hormone (FSH) levels were measured during their first postoperative menstrual cycle.

Results: Patients were grouped according to the use or non-use of propofol as follows: propofol group $(n=39)$ and non-propofol group $(n=41)$. The control group did not undergo surgery. Postoperative E2 levels did not differ between the three groups, but FSH levels were significantly higher in the patients who had undergone surgery compared to controls $(p<0.05)$. Post-hoc analysis of E2 and FSH levels in the propofol and non-propofol groups did not show any significant differences.

Conclusions: The use of propofol did not result in any differences compared to other anesthetic agents in terms of postoperative sex hormone levels after gynecologic surgery. The type of anesthetic agent does not seem to affect the postoperative levels of female sex hormones.

\section{Zusammenfassung \\ $\nabla$}

Einführung: Mehrere Studien haben verschiedene Anästhesiemittel, darunter auch Propofol, in der Follikelflüssigkeit des Ovars nachgewiesen. Bislang ist nur wenig über die Auswirkung von Anästhesiemittel auf die Ovarfunktion bekannt. Ziel dieser Studie war es, mögliche Veränderungen des Sexualhormonspiegels nach einer chirurgischen Intervention mit Propofol-Einsatz aufzuzeigen.

Methoden: Die Daten von 80 Patientinnen, die sich einem chirurgischen Eingriff am Eierstock unterzogen hatten, wurden retrospektiv untersucht. 72 unfruchtbare Frauen dienten als Kontrollgruppe. Einschlusskriterium für die Studie war die postoperative Messung des Östradiolspiegels (E2) und des follikelstimulierenden Hormonspiegels im 1. Zyklus nach dem operativen Eingriff.

Ergebnisse: Patientinnen wurden in 2 Gruppen unterteilt, gemäß des Einsatzes oder Nichteinsatzes von Propofol: Propofol-Gruppe $(n=39)$ und Nicht-Propofol-Gruppe $(\mathrm{n}=41)$. Die Kontrollgruppe wurde nicht operiert. Der postoperative E2-Spiegel unterschied sich nicht zwischen den 3 Gruppen, aber der FSH-Spiegel war signifikant höher in der Gruppe der chirurgisch behandelten Patientinnen verglichen mit der Kontrollgruppe $(\mathrm{p}<0,05)$. Eine Post-hoc-Analyse der E2- und FSH-Spiegel in der Propofol- und der Nicht-Propofol-Gruppe fand keine signifikanten Unterschiede zwischen den beiden Gruppen.

Schlussfolgerungen: Der Einsatz von Propofol hat keine Veränderungen des postoperativen Sexualhormonspiegels ausgelöst im Vergleich zu anderen Anästhesiemitteln. Die Wahl des Anästhesiemittels scheint keine Auswirkungen auf den weiblichen Sexualhormonspiegel nach einem chirurgischen Eingriff zu haben. 


\section{Introduction}

\section{$\nabla$}

Women of reproductive age and their gynecologists have voiced concerns about the postoperative levels of female sex hormones after ovarian surgery. It has been suggested that supra- or subphysiological hormone levels may be due to a compromised blood supply postoperatively or may even result from the use of a specific type of anesthetic agent. Assuming that there are no significant differences in inter- or intra-surgeon surgical skills, the question is whether specific anesthetic agents affect postoperative hormone levels.

General anesthesia is an indispensable part of surgery; it produces amnesia and immobility despite noxious stimulation [1]. Although general anesthesia is considered safe and effective, the different characteristics of anesthetic agents mean that the importance of administering the right anesthetic agent cannot be overemphasized. Propofol is an intravenously administered anesthetic agent and the most common agent used to induce and maintain general anesthesia [2].

It has been reported that the outcomes of several diseases may differ depending on the type of anesthesia - loco-regional versus general anesthesia - used during surgery $[3,4]$. Recently, a number of studies have reported that propofol has been detected in ovarian follicular fluid $[5,6]$ and that the concentration of propofol correlated with the administered dosage and the duration of anesthesia [6]. Propofol has also been reported to increase apoptosis and inhibit the invasion and migration of epithelial ovarian cancer cells $[7,8]$.

It could be hypothesized that ovarian function is affected by propofol. However, little is known about the effect of propofol on ovarian function and whether the intra-ovarian effect of propofol differs from that of other, non-propofol anesthetic agents.

We aimed to investigate differences in sex hormone levels associated with ovarian function according to the use of propofol during anesthesia. In this study, we compared postoperative FSH and estradiol (E2) levels in a control group and in a group which required anesthesia for a surgical procedure. We carried out a subgroup analysis of two groups treated with either propofol or with a non-propofol anesthetic agent. The two subgroups showed no inter-group differences in terms of baseline physical characteristics or surgery-related variables.

\section{Methods \\ $\nabla$}

\section{Study population}

After the study protocol was approved by the Institutional Review Board of Seoul National University Hospital, a retrospective analysis was done of study population consisting of ASA physical status I and II patients who underwent ovarian surgery $(n=80)$. Sex hormone levels were measured postoperatively. All participants were aged 16-40 years and underwent unilateral ovarian surgery with or without total hysterectomy performed under general anesthesia. Patients were classified into one of two groups according to the use or non-use of propofol during anesthesia as follows: propofol group $(\mathrm{n}=39$ ) and non-propofol group $(\mathrm{n}=41)$. The control group consisted of infertile women between the ages of 21 and 40 years who underwent a work-up at Seoul National University Hospital and had no history of gynecologic surgery. Infertility in the control group was due to male factor infertility or tubal factor infertility; ovarian function of the control group was normal and menstrual cycles were regular.
Patients undergoing ovarian surgery and controls were compared and the effects of anesthetic agents on ovarian function were measured. Post-hoc analysis was used to compare the propofol and non-propofol groups. Patients were excluded from the study if they were post-menopausal at the time of surgery or had a previous history of adnexal surgery. Patients were also excluded if they took any hormonal medication such as oral pills within 3 months prior to surgery. All clinical information including blood loss during surgery was collected and retrospectively reviewed.

\section{Techniques for general anesthesia}

Each patient was monitored using standard monitoring techniques (continuous electrocardiography, noninvasive arterial blood pressure, and pulse oximetry). For patients in the propofol group, general anesthesia was induced with propofol (1.5-2 mg/ $\mathrm{kg})$, remifentanil (0.5-1 $\mu \mathrm{g} / \mathrm{kg} / \mathrm{min})$, and vecuronium $(0.1 \mathrm{mg} / \mathrm{kg})$. Tracheal intubation was done and anesthesia was maintained with continuous infusion of propofol (100-250 $\mu \mathrm{g} / \mathrm{kg} / \mathrm{min})$ and remifentanil $(0.1-2 \mu \mathrm{g} / \mathrm{kg} / \mathrm{min})$. For patients in the non-propofol group, anesthesia was induced with thiopental (5-6 mg/ $\mathrm{kg}$ ), fentanyl $(1-2 \mu \mathrm{g} / \mathrm{kg})$, and vecuronium $(0.1 \mathrm{mg} / \mathrm{kg})$. Patients were intubated and anesthesia was maintained with sevoflurane (1-1.5 minimum alveolar anesthetic concentration) in $50 \%$ oxygen in air and supplemental bolus doses of fentanyl (1-2 $\mu \mathrm{g} / \mathrm{kg})$.

For each patient in both groups, muscle relaxation was achieved with supplemental 1-2 mg doses of vecuronium. A forced air warming device was used to maintain normothermia. To maintain mean arterial blood pressure and heart rate within $20 \%$ of baseline values, the depth of anesthesia was controlled with fluid bolus and drug infusion according to the attending anesthesiologist's assessment.

\section{Measurement of serum hormone levels}

Postoperative serum hormone levels were measured on day 2 to 5 of the first menstrual cycle after surgery. In the control group, hormones were measured on cycle day 2 to 5 during the infertility work-up. Serum estradiol (E2) assay was performed using a radioimmunoassay kit (Siemens Healthcare Diagnostics Inc., Deerfield, IL, USA) and serum FSH was measured using an immunoradiometric assay kit (Siemens Healthcare Diagnostics Inc.). Minimum detection limits were $8 \mathrm{pg} / \mathrm{mL}$ and $0.06 \mathrm{mIU} / \mathrm{mL}$, respectively. The intra- and inter-assay coefficients of variation of each assay ranged from 2.2 to $4.2 \%$.

\section{Statistical analysis}

All data were expressed as mean and standard error or percentage. All statistical analyses were performed using the Statistical Package for the Social Sciences, version 12.0 (SPSS Inc., Chicago, IL, USA). The power of the present study was 0.89 and the effect size was 0.29 with a $5 \%$ type I error. Demographic data were analyzed by Student's t-test and analysis of variance or $X^{2}$ test, depending on the type of anesthesia. The differences in hormone levels according to the type of anesthesia were tested after adjustment for potential confounding factors, using analysis of covariance. A p-value of less than 0.05 was considered significant for all analyses. 
Table 1 Baseline characteristics according the type of anesthesia in patients who had gynecologic surgery.

\begin{tabular}{|c|c|c|c|c|}
\hline Variables & Non-propofol $(n=41)$ & Intravenous propofol $(n=39)$ & Control $(n=72)$ & p value \\
\hline Age (years) & $32.5 \pm 1.0$ & $31.6 \pm 1.0$ & $32.6 \pm 0.4$ & $0.61^{*}$ \\
\hline Body mass index $\left(\mathrm{kg} / \mathrm{m}^{2}\right)$ & $22.6 \pm 0.4$ & $22.0 \pm 0.6$ & $21.2 \pm 0.3$ & $0.06^{*}$ \\
\hline \multicolumn{5}{|l|}{ Number of live births } \\
\hline$>0$ & $57.5 \%$ & $64.1 \%$ & & 0.90 \\
\hline > 1 & $15.0 \%$ & $15.4 \%$ & & \\
\hline$\Rightarrow \geq 2$ & $27.5 \%$ & $20.5 \%$ & & \\
\hline Duration of surgery (min) & $151.0 \pm 17.1$ & $160.0 \pm 13.8$ & & 0.69 \\
\hline Estimated blood loss (ml) & $453.8 \pm 41.5$ & $468.2 \pm 65.6$ & & 0.85 \\
\hline Concomitant hysterectomy (\%) & $36.6 \%$ & $25.6 \%$ & & 0.29 \\
\hline Pelviscopic surgery (\%) & $17.1 \%$ & $10.3 \%$ & & 0.38 \\
\hline
\end{tabular}

Data are presented as mean \pm SE or as a percentage.

* $p$ value calculated using analysis of variance and $p$ value by $t$-test and $x^{2}$ test.

Table 2 Postoperative hormone levels according to the type of anesthesia.

\begin{tabular}{|lllcc} 
Hormones & Non-propofol $(\mathbf{n = 4 1 )}$ & Intravenous propofol $(\mathbf{n = 3 9 )}$ & Control $(\mathbf{n}=\mathbf{7 2})$ & $\mathbf{p}$ value \\
FSH $(\mathrm{mlU} / \mathrm{mL})$ & $15.6 \pm 2.3^{*}$ & $14.8 \pm 2.3^{\dagger}$ & $7.0 \pm 1.7^{*}, \boldsymbol{T}^{+}$ & $<0.05$ \\
\hline Estradiol $(\mathrm{pg} / \mathrm{mL})$ & $42.0 \pm 5.6$ & $33.2 \pm 5.6$ & $33.9 \pm 4.0$ & 0.44 \\
\hline
\end{tabular}

FSH: follicle stimulating hormone. Data are presented as mean \pm SE. $p$ value calculated by t-test and $x^{2}$ test. Values adjusted for age and body mass index. ${ }^{*},: p<0.01$

\section{Results \\ $\nabla$}

\section{Baseline characteristics of study subjects}

The baseline characteristics were compared between the control, propofol and non-propofol groups ( $\bullet$ Table 1$)$. There was no significant difference in age between the three groups (control vs. propofol vs. non-propofol: $32.6 \pm 0.4$ years vs. $31.6 \pm 1.0$ years vs. $32.5 \pm 1.0$ years). Body mass index (control vs. propofol vs. nonpropofol: $21.2 \pm 0.3 \mathrm{~kg} / \mathrm{m}^{2}$ vs. $22.0 \pm 0.6 \mathrm{~kg} / \mathrm{m}^{2}$ vs. $22.6 \pm 0.4 \mathrm{~kg} /$ $\mathrm{m}^{2}$ ) and parity also did not differ significantly.

\section{Comparison of surgical variables between propofol and non-propofol groups}

Surgical variables were compared for the propofol and non-propofol groups ( Table 1). The duration of surgery did not differ significantly between the two groups (propofol vs. non-propofol: $160.0 \pm 13.8 \mathrm{~min}$ vs. $151.0 \pm 17.1 \mathrm{~min}$ ). The estimated blood loss during surgery did not differ significantly (propofol vs. non-propofol: $468.2 \pm 65.6 \mathrm{~mL}$ vs. $453.8 \pm 41.5 \mathrm{~mL}$ ). The percentage of patients who underwent simultaneous hysterectomy did not differ significantly between the two groups (propofol vs. non-propofol: 25.6 vs. $36.6 \%$ ). The percentage of pelviscopic surgeries also did not differ significantly (propofol vs. non-propofol: 10.3 vs. $17.1 \%)$.

\section{Postoperative hormone levels according}

to the type of anesthesia

Although E2 levels did not differ significantly between the three groups, FSH levels differed significantly between the control group and the group which had undergone surgery $(\mathrm{p}<0.05)$. FSH levels were significantly higher in the group which had undergone surgery compared to the control group (control vs. propofol: $7.0 \pm 1.7 \mathrm{mIU} / \mathrm{mL}$ vs. $14.8 \pm 2.3 \mathrm{mIU} / \mathrm{mL}, \mathrm{p}<0.01$; control vs. non-propofol: $7.0 \pm 1.7 \mathrm{mIU} / \mathrm{mL}$ vs. $15.6 \pm 2.3 \mathrm{mIU} / \mathrm{mL}$ ) ( Table 2). Post-hoc analysis of E2 (propofol vs. non-propofol: $33.2 \pm 5.6 \mathrm{pg} / \mathrm{mL}$ vs. $42.0 \pm 5.6 \mathrm{pg} / \mathrm{mL}$ ) and FSH (propofol vs. non- propofol: $14.8 \pm 2.3 \mathrm{mIU} / \mathrm{mL}$ vs. $15.6 \pm 2.3 \mathrm{mIU} / \mathrm{mL}$ ) levels show no significant differences between the propofol and non-propofol groups.

\section{Discussion \\ $\nabla$}

For gynecologists and patients of reproductive age, it is important to understand the potential changes in postoperative levels of female sex hormones after ovarian surgery. One of the questions in this context is whether a specific anesthetic agent might have a greater impact on postoperative hormone levels. To the best of our knowledge, our investigation is the first of this kind. General anesthesia is used in conventional surgery to block sensory, motor and sympathetic nerve conduction, resulting in unconsciousness, analgesia, and the suppression of autonomic reflexes. A variety of drugs are used for anesthesia in current practice, and propofol is one of the most commonly used intravenous agents administered by continuous infusion or intermittent bolus injection.

Propofol distributes rapidly into the peripheral tissues including the central nervous system due to its high lipophilicity [2]. Intriguingly, it has also been found in ovarian follicular fluid [6,9]. Serum propofol levels fluctuate during surgery whereas follicular fluid levels steadily increase in proportion to the administered dose of propofol $[6,9]$. It has been suggested that the oocyte retrieval procedure should be kept as short as possible, in order to minimize the accumulation of the anesthetic agent in follicular fluid [9]. These findings suggest that propofol accumulates in ovarian follicular fluid; however, the ovarian clearance rate of propofol has not yet been elucidated.

A dose- and time-dependent detrimental effect of propofol has been demonstrated for the in vitro maturation of oocytes and cleavage rates of embryos in animal models $[10,11]$. In this context, residual propofol after surgery may affect postoperative ovarian function. To date, our current report is the first study to 
investigate whether sex hormone levels differ postoperatively according to the use or non-use of anesthetic agent propofol.

Marana et al. [12] recently compared the levels of neuroendocrine stress hormones including thyroid stimulating hormone and prolactin during intravenous anesthesia using propofol versus inhalational anesthesia. They found that increased prolactin levels were maintained for four hours after the end of surgery. When prolactin levels rise, the hypothalamus releases more dopamine, and increased dopamine levels suppress the release of gonadotropin-releasing hormone and FSH $[13,14]$. In another report, the levels of stress hormones such as epinephrine and cortisol were found to be influenced by the type of anesthetic agent used [15]. In contrast to these studies, our study found that E2 and FSH levels measured during the first postoperative menstrual cycle did not differ significantly between the propofol and nonpropofol groups. It could be inferred from this that sex hormone responses to anesthetic agents may differ from those of neuroendocrine stress hormones.

Ovarian reserve, i.e., the functional capacity of the ovary to provide oocytes, can decrease after ovarian surgery. The most common test of ovarian reserve consists of measuring E2 and FSH levels in the early follicular phase, as was done in the present study. An elevated early follicular phase E2 level (usually greater than $80 \mathrm{pg} / \mathrm{mL}$ ) predicts ovarian follicular depletion [14,16-18]. Increased levels of E2 can suppress pituitary FSH secretion, possibly masking elevated FSH levels that would indicate decreased ovarian reserve. High FSH levels represent a decrease in fertility; however, FSH levels can vary between different laboratories due to the different FSH assay methods used [14,19]. Anti-Müllerian hormone $(\mathrm{AMH})$, which is known to decline with reproductive aging $[20,21]$, has been reported to decrease after ovarian cystectomy and to recover by three months postoperatively $[22,23]$.

Our study has a few limitations. Firstly, the study was a retrospective study and the inclusion criteria restricted the study population to women undergoing ovarian surgery. The surgical procedures themselves may affect the sex hormone levels and blur the effects of anesthetic agents on ovarian function. Secondly, preoperative serial FSH and E2 levels were not measured, since these assays were not routine in our protocols. To compensate for this weakness, the hormone values of the groups who underwent surgery were compared to those of a control group which did not undergo surgery. Thirdly, the present study did not measure $\mathrm{AMH}$, a more powerful marker of ovarian reserve. AMH has minimal inter- or intra-cyclic variability, and can be measured irrespective of the menstrual cycle $[24,25]$. It has since been adopted in our clinical setting, but at the time we were not able to analyze and present data that included AMH. Finally, the data would be more meaningful if postoperative FSH and E2 levels were measured serially over several menstrual cycles. However, we could not retrieve the relevant data due to the limitation of the retrospective design of our study.

\section{Conclusions}

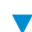

Overall, propofol did not differ from other anesthetic agents in terms of postoperative ovarian function after gynecologic surgery. The type of anesthetic agent did not seem to affect the postoperative levels of female sex hormones. Further prospective studies with comprehensive serial measurements of sex hormone levels are needed.

\section{Acknowledgements}

$\nabla$

This research was funded by grants from the Ministry of Education (NRF-2013R1A1A2009521), the Seoul National University Hospital Research fund (0420150910) and the Ministry of Health and Welfare (HI14C2259), Republic of Korea.

\section{Conflict of Interest \\ $\nabla$}

The authors have no conflicts of interest to report.

\section{References}

1 Urban BW, Bleckwenn M. Concepts and correlations relevant to general anaesthesia. Br J Anaesth 2002; 89: 3-16

2 Eger EI 2nd. Characteristics of anesthetic agents used for induction and maintenance of general anesthesia. Am J Health Syst Pharm 2004; 61 (Suppl. 4): S3-S10

3 Bonnet F, Marret E. Influence of anaesthetic and analgesic techniques on outcome after surgery. Br J Anaesth 2005; 95: 52-58

4 Sessler DI, Ben-Eliyahu S, Mascha EJ et al. Can regional analgesia reduce the risk of recurrence after breast cancer? Methodology of a multicenter randomized trial. Contemp Clin Trials 2008; 29: 517-526

5 Ben-Shlomo I, Moskovich R, Golan J et al. The effect of propofol anaesthesia on oocyte fertilization and early embryo quality. Hum Reprod 2000; 15: 2197-2199

6 Christiaens F, Janssenswillen C, Verborgh C et al. Propofol concentrations in follicular fluid during general anaesthesia for transvaginal oocyte retrieval. Hum Reprod 1999; 14: 345-348

7 Su Z, Hou XK, Wen QP. Propofol induces apoptosis of epithelial ovarian cancer cells by upregulation of microRNA let-7i expression. Eur J Gynaecol Oncol 2014; 35: 688-691

8 Wang $P$, Chen J, Mu LH et al. Propofol inhibits invasion and enhances paclitaxel- induced apoptosis in ovarian cancer cells through the suppression of the transcription factor slug. Eur Rev Med Pharmacol Sci 2013; 17: 1722-1729

9 Coetsier T, Dhont M, De Sutter P et al. Propofol anaesthesia for ultrasound guided oocyte retrieval: accumulation of the anaesthetic agent in follicular fluid. Hum Reprod 1992; 7: 1422-1424

10 Alsalili $M$, Thornton S, Fleming $S$. The effect of the anaesthetic, Propofol, on in-vitro oocyte maturation, fertilization and cleavage in mice. Hum Reprod 1997; 12: 1271-1274

11 Janssenswillen C, Christiaens F, Camu F et al. The effect of propofol on parthenogenetic activation, in vitro fertilization and early development of mouse oocytes. Fertil Steril 1997; 67: 769-774

12 Marana E, Colicci S, Meo F et al. Neuroendocrine stress response in gynecological laparoscopy: TIVA with propofol versus sevoflurane anesthesia. J Clin Anesth 2010; 22: 250-255

13 Andersen AN, Hagen C, Lange Pet al. Dopaminergic regulation of gonadotropin levels and pulsatility in normal women. Fertil Steril 1987; 47: 391-397

14 Speroff L, Fritz MA. Clinical gynecologic Endocrinology and Infertility. Chapter 5: Neuroendocrinology. Philadelphia: Lippincott Williams \& Wilkins; 2005: 154, 1020

15 Marana E, Scambia G, Colicci S et al. Leptin and perioperative neuroendocrine stress response with two different anaesthetic techniques. Acta Anaesthesiol Scand 2008; 52: 541-546

16 Buyalos RP, Daneshmand S, Brzechffa PR. Basal estradiol and folliclestimulating hormone predict fecundity in women of advanced reproductive age undergoing ovulation induction therapy. Fertil Steril 1997; 68: 272-277

17 Licciardi FL, Liu HC, Rosenwaks Z. Day 3 estradiol serum concentrations as prognosticators of ovarian stimulation response and pregnancy outcome in patients undergoing in vitro fertilization. Fertil Steril 1995; 64: 991-994

18 Smotrich DB, Widra EA, Gindoff PR et al. Prognostic value of day 3 estradiol on in vitro fertilization outcome. Fertil Steril 1995; 64: 1136-1140

19 Scott RT jr., Hofmann GE. Prognostic assessment of ovarian reserve. Fertil Steril 1995; 63: 1-11

20 Themmen AP. Anti-Mullerian hormone: its role in follicular growth initiation and survival and as an ovarian reserve marker. J Natl Cancer Inst Monogr 2005; 34: 18-21 
21 van Rooij IA, Broekmans FJ, Scheffer GJ et al. Serum antimullerian hormone levels best reflect the reproductive decline with age in normal women with proven fertility: a longitudinal study. Fertil Steril 2005; 83: 979-987

22 Chang HJ, Han SH, Lee JR et al. Impact of laparoscopic cystectomy on ovarian reserve: serial changes of serum anti-Mullerian hormone levels. Fertil Steril 2010; 94: 343-349
23 Iwase A, Hirokawa W, Goto M et al. Serum anti-Mullerian hormone level is a useful marker for evaluating the impact of laparoscopic cystectomy on ovarian reserve. Fertil Steril 2010; 94: 2846-2849

24 Pavlik R, Hecht S, Walter C et al. Anti-Müller-Hormon (AMH) als prognostischer Faktor der kontrollierten ovariellen Hyperstimulation. Geburtsh Frauenheilk 2008; 68 - PO_Endo_03_11; DOI: 10.1055/s0028-1089181

25 Reisenbüchler C, Kast K, Lauterbach A et al. Messabweichungen in der AMH-Bestimmung. Geburtsh Frauenheilk 2014; 74 - A14; DOI: $10.1055 / \mathrm{s}-0034-1376474$ 